\title{
The Traveling Buddha
}

\author{
Chuyu Guo ${ }^{1, a}$
}

\author{
${ }^{1}$ Stevenson School, Pebble Beach, 93953, United States \\ a18610308111@163.com
}

\begin{abstract}
Mogao Buddhist Caves, located in Dunhuang China, are important witnesses of cultural, religious and commercial exchanges throughout history. Buddhism, was first introduced in Dunhuang region and then further developed in other places in China, and became one of the most significant religions in China until today. How did this exotic religion became a part of Chinese culture? This essay will answer the aforementioned question by analyzing the evidences in Mogao Caves in correspondence with their time periods to unwind the development of Buddhism in China.
\end{abstract}

Keywords: Dunhuang, Mogao Caves, Spread of Buddhism

\section{INTRODUCTION}

Mogao Caves, located in Dunhuang city, are large scales of buddhist grottos incessantly builded on the gobi cliffs for thousand years from 366AD to Yuan Dynasty, containing invaluable murals, statues, and scriptures. These art pieces provides visual historical sources such as cultures, religions, politics, and ethnicity relations. Besides Han Chinese, the art elements in Mogao Caves merged the culture of people with different nationalities and ethnicities such as the Indians, Tibetans, and Sogdians together [1]. Therefore, these Buddhist cave offers spectacular evidences of history.

Buddhism was gradually introduced into China through the Silk Road from ancient India at the beginning of Eastern Han Dynasty, around 60-70AD. Through a couple hundred years of cultural selection, adaptation and sinicization, Buddhism has become one of the most influential religions in China with thriving buddhist religion, culture, and art development. Muralsand statues in Mogao Caves, along with the development of the Silk Road, reflects the ethnic diversity, adaptation and localization, and growing religious attachment throughout time.

\section{ETHNIC DIVERSITY}

Dunhuang, a city in Gansu Province, China, is located in the northwestern frontier garrison of China as an important stop of the Silk Road in ancient times. It was in 121BC when Emperor Wu-ti of Han Dynasty unified the Hexi corridor that the area of Dunhuang officially became a permanent territory of China until today, an important geographical location connecting China all the way to the west and controlling the entrance to Hexi corridor which could lead to the capital of Chang'an. The Silk Road was officially started with Zhang Qian's second envoy to the west in 119BC, bringing numerous Chinese goods with him andestablishing official bonds with other nations. Since then, the Dunhuang area, as an important stop along the Silk Road, has become an extremely prosperous international commerce center with diverse people.

Under this circumstance, culture and religion spread anddeveloped along the commerce channels of the Silk Road.

Buddha Shakyamuni is a significant buddhist figure who created the religion of Buddhism. It is said inthe buddhist tale that on the date of his birth, celestial dragons came to bathe him with fragrant water from the sky. The merit of bathing the Buddha has blessings suchas getting rid of diseases and purifying the body and mind [2]. A relief sculpture collected in Peshawar museum displays a scene of two dragons in humanoid forms bathing for the infant Shakyamuni. This carving exemplifies the tale of the birth of Shakyamuni from Gandhara region, that the infant Shakyamuni is bathed by two dragons. However, when Buddhism gradually spread to China, the numbers of dragons in the tale changed. According to a Tang silk painting from Mogao cave 17 currently collected in British Museum, the number of celestial dragons that bathed Shakyamuni increased from 2 to 9 . Until today there still exists the folk story and the idiom of "Ninedragons bathing the baby buddha" in China. The number 
"nine" in Chinese culture has the symbolic and sacred meaning of "sky" or"supremacy", thus was connected to the imperial power in ancient times. Therefore, the change from two of dragons to nine dragons is not only a simple number change, but more importantly, a proof of Buddha's status in Chinese people's mind and the administrative support to Buddhism.

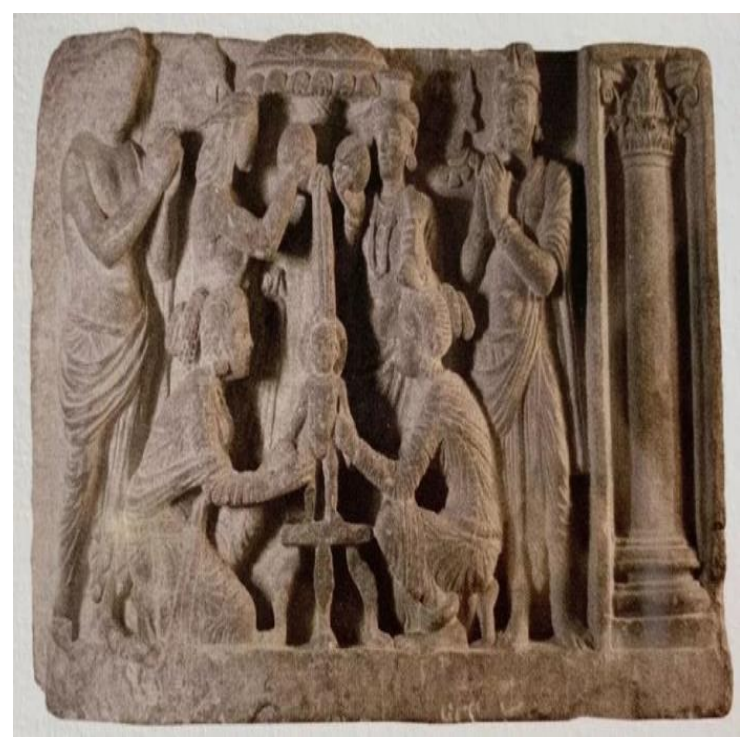

Figure1 Bathing the Buddha Peshawar Museum

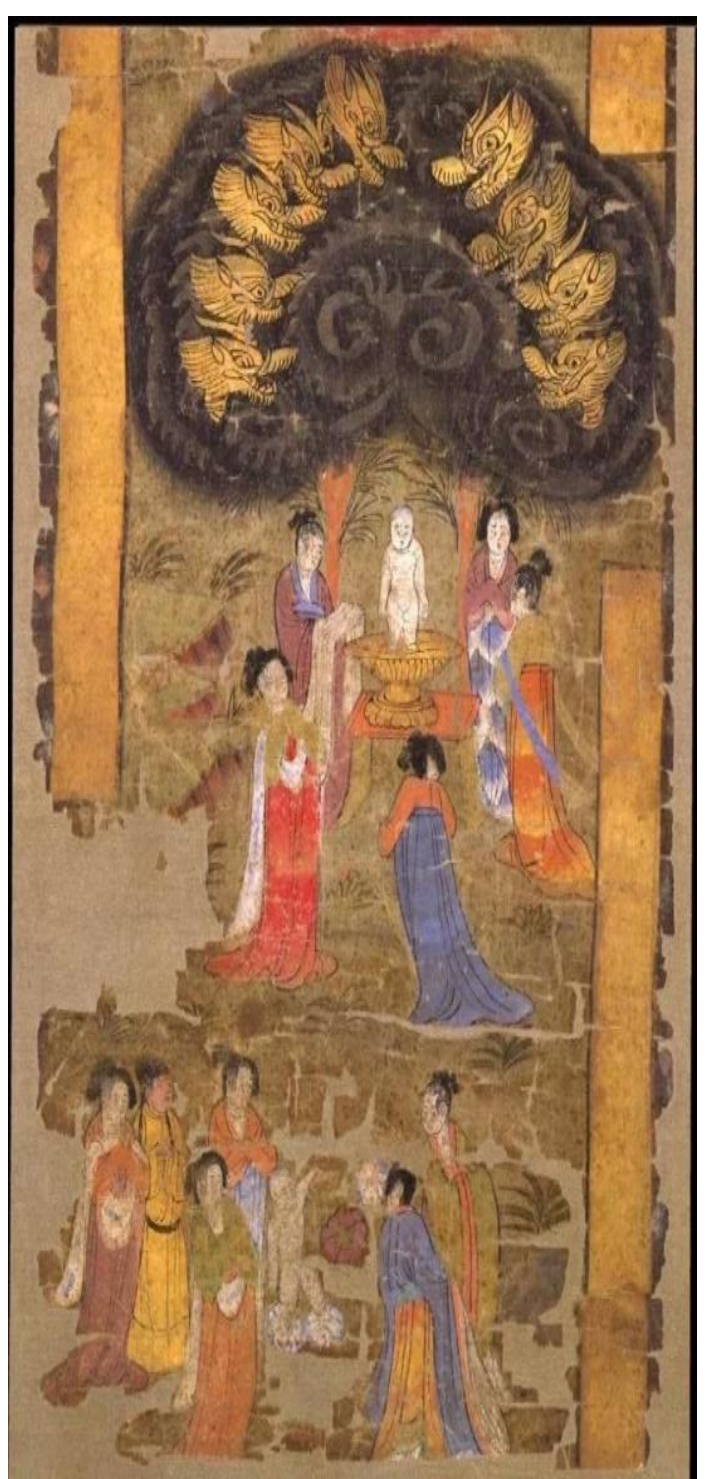

Figure 2 Bathing the Buddha Library Cave of Mogao Caves British Museum

Another example of Sinicization of Buddhism includes the Feminization of Bodhisattva. In Buddhism, a Bodhisattva is an enlightened being who is on the wayof becoming a Buddha, but choses to stay in samsara to save suffering lives. Mogao Cave 275 is one of the earliest caves left from Northern Liang Dynasty, 397-

439. In the middle of Cave 275 seated a statue of Bodhisattva of Maitreya. This Bodhisattva is 3.34 meters high with robust body figure, solemn expression, high nose bridge, and round eyes. This traces western male appearances from Indian region. The Bodhisattva's clothings is consistent with that of early Bodhisattvas from the Western Regions: bare upper body with necklaces or ribbons, lower body wrapped with skirts. The corresponds with buddhist art from Gandhara regions, proving the cultural exchange in Dunhuang areas and the introduction of Buddhism from the west [3]. 


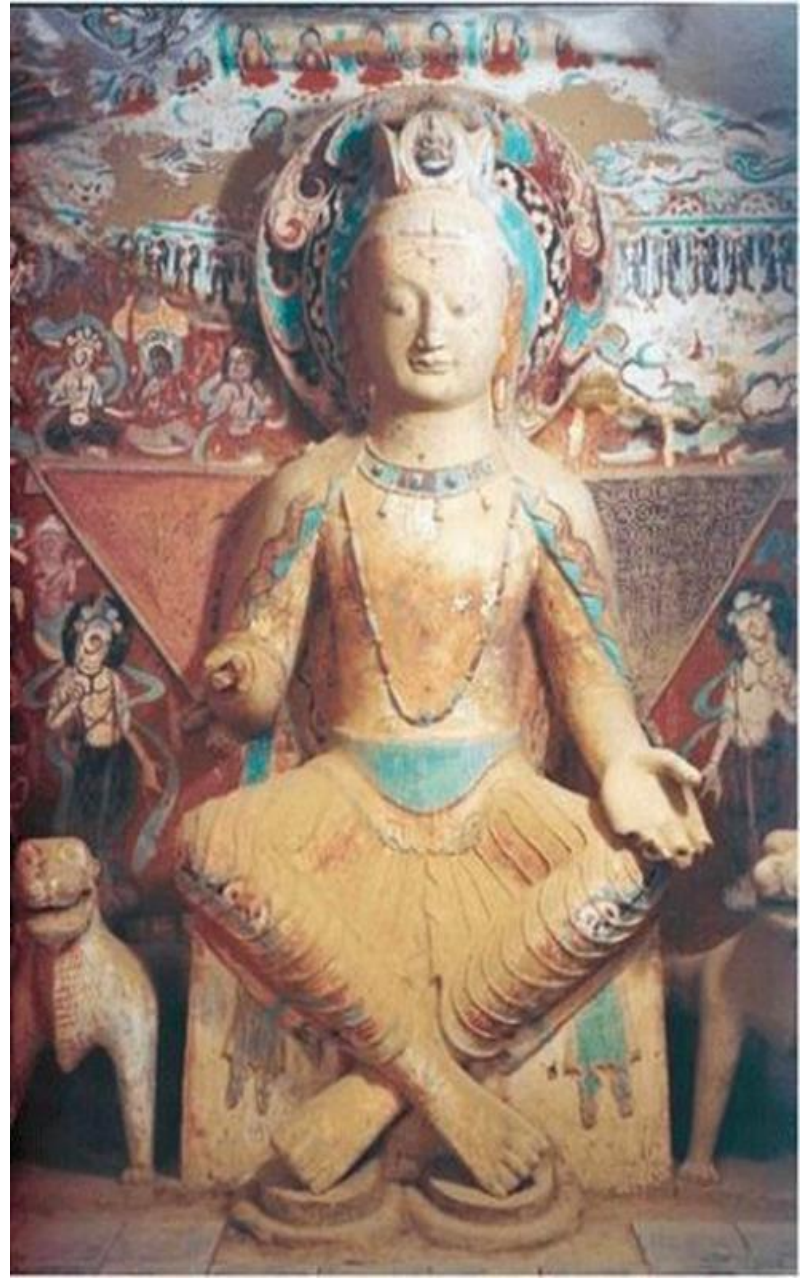

Figure 3 Statue of Bodhisattva Mogao Cave 275, Northern Liang Dynasty

With Buddhism completing the process of indigenization and reaching its artistic maturity in China around Tang Dynasty, the appearance of the Bodhisattva also changed. In order for people to understand Bodhisattvas' role of saving the suffering beings and convince people their kindness and mercy, the figure of Bodhisattvas gradually became more feminized. Mercy and selfless compassionate, Bodhisattvas' characteristics, is the symbol of maternal love in Chinese value. Therefore, the feminization of Bodhisattva corresponds devotion to Buddhism with filial piety to motherhood. Take the Bodhisattva on the mural of Mogao Cave 57 from the Tang Dynasty, for example. This Bodhisattva is one of the most classic, representative, and beautiful Bodhisattva in Mogao Caves. Painted in early Tang Dynasty, this Bodhisattva had obvious female features of a smooth body shape and a gentle facial appearance. Her crown and ornaments made by all kinds of precious stones underlined her delicacy and gracefulness. At this time period, Bodhisattva has completely changed into a feminine figure in Chinese people's understanding, and Buddhism has completely become a part of Chinese culture.

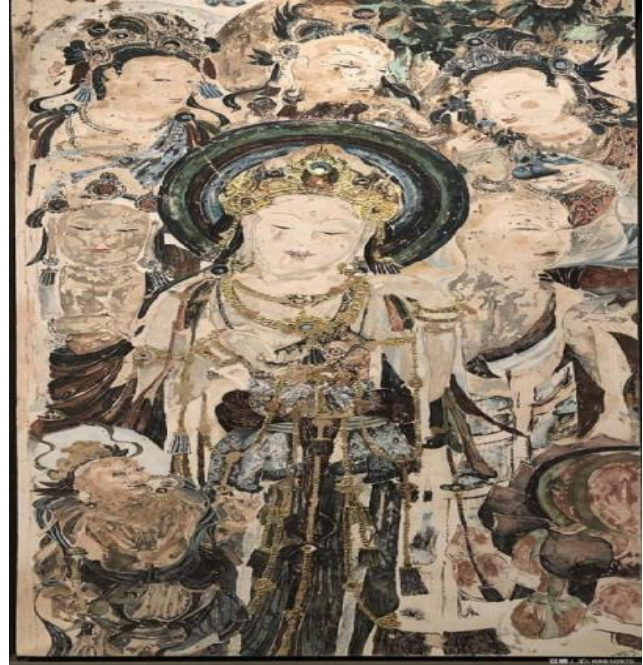

Figure 4, Mural of Budhisattva Mogao Cave 57, Tang Dynasty

\section{GROWING RELIGIOUS ATTACHMENT}

The donors of these Buddhist caves are the ones who worship Buddhism and provide funds for the construction of the caves. Instead of given orders by thegovernment to initiate official construction projects, people in Dunhuang spontaneously and voluntarily devoted themselves to cave building. These donors vary from all social classes and ethnicities including local officials, businessmen, noble women, monks, common men, and people from other ethnicities besides Han Chinese. The figures of the cave donors were usually painted on walls of their caves in order to show their devoutness and merit to Buddhism. Due to historical changes in society, religions, aesthetics and other factors, the portrait of donors on murals have obvious characteristics of their own time period.

Therefore, the portraits of cave donors are very crucial to the studies of the social structure and demographics, the spread of religions, and the cultural exchange alongthe Silk Road.

In the mid-Tang Dynasty, Dunhuang was occupied by the Tubo regime for 60 to 70 years. During their reign of the area, they implemented Tubo policies coercively, but actively promoted Buddhism. Cave 359 was a Buddhist cave built in this time period. The donors were painted on the bottom of four walls of the cave, but except the monks, the male donors are all wearing Tubo clothings, while women are wearing Tangsuits [4]. The ancestors of the cave donors are painted on the eastern wall with Tang suits, which substantiates that the family of cave donors are local Han Chinese from Dunhuang instead of Tibetans or people from other ethnicities. This indicates that the male donors of the caves were restricted by the Tubo policy that all males had to wear Tubo clothings. The coexistence of Tubo and Tang clothings in the cave reflects the further strengthening of ethnicity integration in the area, and local people's resistance to Tubo tyranny 
and nationality recognition deep in their heart [5]. Painting the entire family onto the murals indicates that Buddhism had

become people's mental sanctuary during the Tubo reign of the area, meanwhile proving the prosperity of Buddhism in the area at the time period. This secularization of Buddhist caves' function also reflects people's strong emotion and yearn for receiving more intimacy with the Buddhas, paving the road for the expansion of cave functions and the development of relation between people and Buddhas in the future time period.

Gradually staring from the Tang Dynasty, people are not satisfied with simple displaying donor figures onthe bottom of murals anymore, so more vivid and magnified forms of donor figures appeared. In late TangDynasty, donors' merits and family added onto the Buddhist caves' significance. Zhang Yichao, a local resident at Duhuang, led a rebellion to overthrown the Tibetan Empire and returned the Hexi areas back to Tang's regime. Since he met people's eagerness of returning to Tang's govern and was appoint as a militarygovernor by the Tang Emperor, his family were well- respected for their heavenly contribution. Therefore, the Zhang family broke the tradition forms of donor figures, and painted scenes of Zhang Yichao leading military to fight Tibetans on the murals of Cave 156, making Buddhist caves for worshiping Buddhism have functions of highlighting one's merit or serving as family memorials. Influenced by his family cave, many future caves followed Zhang's Cave 156 and recorded the donor families' glory.

\section{HISTORY IN THE MURAL}

The content painted on the murals of Buddhist Caves in Dunhuang are important historical sources for reference of religious and cultural development. One type of paintings of the murals are story paintings, which recorded stories of historical scenes. An exampleproving the development is the mural of Cave 323, showing the story of Zhang Qian's second envoy to thewest and monk Kang Senghui's voyage down to Jiangnan region to spread Buddhism.

The story of Zhang Qian is composed by three pieces of murals: Wu-ti worshiping two statues conquered from Xiongnu, Zhang Qian bidding farewell to Wu-ti, and Zhang Qian's mission arriving at the gateof Daxia. In the story, Wu-ti liked the two statues so heenshrined and worshiped them, but he does not know their deities. Therefore, he sent Zhang Qian off, asking him to inquire about the statues' information when journeying to the west. Then, Zhang Qian arrived at Daxia nation with two monks standing in front of the gate welcoming him, and from Daxia he learnt that the two statues were Buddha figures [6]. This story corresponds with the historical record of Zhang Qian's second envoy to the west, which he was originally to form ally with $\mathrm{Wu}$-Sun people to resist Xiongnu together. Although the original commission failed to achieve, his two journeys connected nations in the westwith Han China, bringing customs, cultures, religions, and merchandises all together, exchanging and developing along the Silk Road.

Another story presents on the mural of Cave 323 isthe reverent monk Kang Senghui's voyage down to Jiangnan to spread the ideals of Buddhism. This story took place in the period of Three Kingdoms, where Buddhism was yet popularized in Jiangnan, southern regions of China. The story was constituted by four groups of painting, showing that Kang Senghui went down south to the Wu Kingdom by boat, and the emperor received him, believed his preachings, and started to build Buddhist temple. In history record, Kang Senghui was an erudite monk who preached in theJiangnan areas and had a significant role in the history of Buddhism spreading down to the south. The temple painted on the mural is called "Jianchu Temple", which is the very first Buddhist temple in Jiangnan, laying foundation for the spread of Buddhism [7]. Highly regarded by the Emperor, this new religion of Buddhismstarted to thrive in the south. This is a perfect example illustrating that Buddhism, a foreign religion, was further spread into different areas and adopted by Chinese, becoming one of the most important religions in China.

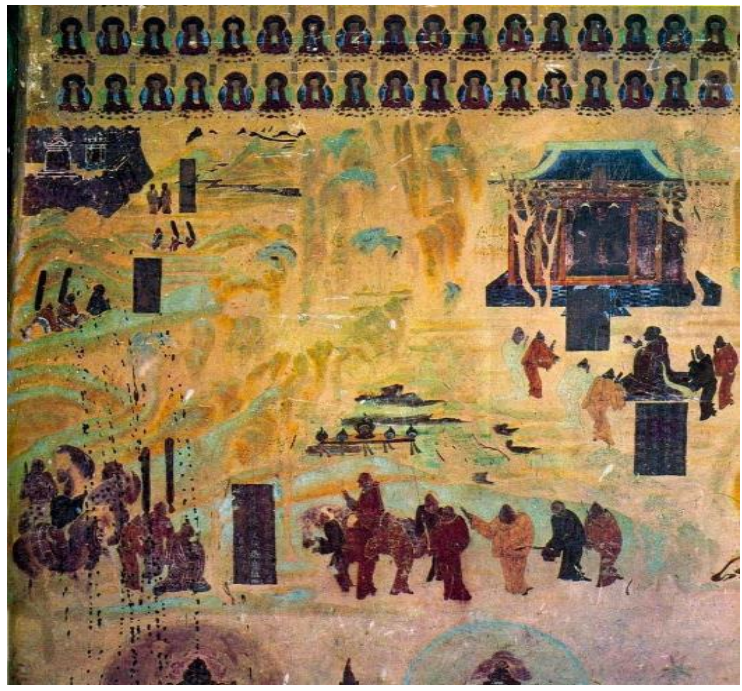

Figure 5 Zhang Qian's Second Envoy to the West Mogao Cave 323, Tang Dynasty 


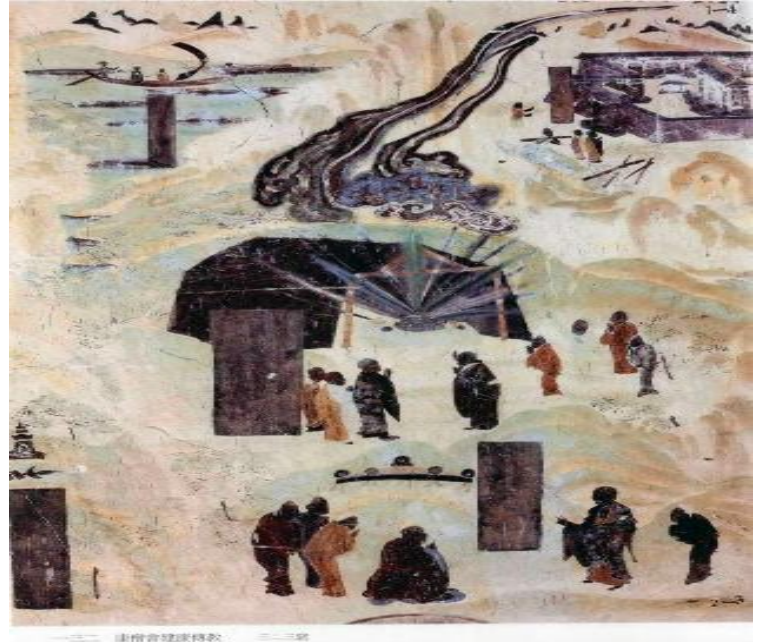

Figure 6 Kang Senghui's Journey Down to Jianan Mogao Cave 323, Tang Dynasty

\section{CONCLUSION}

In this essay, we see how the murals and statues of Mogao Caves delivered the historical information of of interaction and exchange in Dunhuang. We also see people's open attitude to exotic matters here, and how they adopted and indigenized them, contributing to the prosperity of culture in the region. Dunhuang Murals reflected that culture, with religion as its carrier, spreaded and developed along the commerce of the SilkRoad. Art in Dunhuang needs more attention from the world, that they reveal the past glory and indicates the future prospect, showing people the brilliancy of this convergence and exchange of civilization.

\section{REFERENCES}

[1] United Nations Educational, Scientific and Cultural Organization.() Mogao Caves. https://whc.unesco.org/en/list/440/\#: :text=As\%20 evidence $\% 20 \mathrm{of} \% 20$ the $\% 20$ evolution, daily $\% 20 \mathrm{dre}$ ss\%20in\%20western\%20China.

[2] Lingyen Mountain Temple (Canada).The meaning ofBathing the Buddha. https://lymtcanada.com/2019/04/the-meaning-ofthe-verses-of-bathing-the-buddha/

[3] Hong Kong Heritage Museum. (2014) Mogao Cave275.

https://www.heritagemuseum.gov.hk/en_US/web/h m/exhibitions/data/exid218/exhibit_1.html\#top

[4] Zhang, X.(2008) The Development and Evolution ofDonor Portraits in Mogao Caves - Centered on the Investigation of Buddhist History [J]. Journal of Dunhuang Studies, No.62(04):93-103.
[5] Sha,W.(2003) Investigation on Portraits of Donors in Dunhuang Grottoes During the Reign of Tubo[J].China Tibetology

[6] Dunhuang Foundation. (2017) Dunhuang Historical Art: Cave323.

http://dunhuangfoundation.us/blog/2017/10/2/dunh uang-historical-art-cave-323-and-the-history-ofbuddhism-in-china

[7] Xun San Guo.(2017) Jianchu Temple. https://searchsanguo.blogspot.com/2017/12/blogpost $22 . \mathrm{html} \mathrm{m}=0$ 